\title{
LAS FRONTERAS DE EUROPA CENTRAL Y ORIENTAL *
}

\author{
Por \\ Michel Sivignon**
}

\begin{abstract}
RESUMEN
La reubicación reciente de las fronteras en Europa parece responder a procesos marcados por los antiguos límites teóricamente inexistentes de los impreios ya desaparecidos (alemán, austro-húngaro, ruso-otomano), pero que en los acontecimientos más recientes han hecho sentir su influencia. Aquí pretendemos realizar una tipología de las nuevas fronteras europeas y caracterizar su funcionamiento.
\end{abstract}

\begin{abstract}
The recent relocation of the borders in Europe appears to be part a process strongly by the ancient, theoretically boundaries of now-venished empires (German, AustroHungarian, Russian-Ottoman), but which in recent events have made their influence felt. Here we attempt to give a typology for the new European borders, and to characterize their function.
\end{abstract}

El cuerpo de Europa parece marcado no solamente por las fronteras actuales, sino también por las cicatrices de las fronteras antiguas. Recordemos la importancia de dichas fronteras en la organización territorial de países tales como Polonia, Rumania y Yugoslavia, fronteras teóricamente borradas de los imperios hoy desaparecidos (alemán, austro-húngaro, ruso otomano).

* Documento presentado en el evento "Fronteras en perspectiva internacional" realizado en la Universidad Autónoma de Baja California, los días 17 y 18 de noviembrede 1997.

** Profesor de la Universidad de París X-Nanterre. 
En los acontecimientos más recientes (partición pacífica de la República Checa y Eslovaquia, estallido de Yugoslavia) parece que son las fronteras antiguas las que se reactivan y vuelven a importar : la existente entre Austria y Hungría en el seno del imperio de Habsburgo, la del imperio austro-húngaro y la del imperio otomano. Otras reaparecen en países donde estaban escondidas tales como Rumania y Polonia. Otras más sí son nuevas, como las que existen en algunas regiones de Yugoslavia.

En el proceso de reorganización política tanto de la Europa central como oriental, cuyas fronteras políticas son en cierta manera el aspecto más visible, los territorios nacionales mismos son transformados en su equilibrio interno. Estas dos zonas de Europa han cambiado según centros de impulsión ajenos ubicados al oeste y muy parcialmente al sur. Cada territorio nacional se arregla respecto a ese nuevo rumbo de los cambios. La margen occidental de los diferentes países mencionados, está afectada por una dinámica de desarrollo, mientras que la margen oriental tiene dificultades profundas.

\section{RASGOS CARACTERÍSTICOS DEL FUNCIONAMIENTO DE LAS FRONTERAS DEL BLOQUE COMUNISTA}

Las fronteras políticas presentaban en el bloque comunista, rasgos característicos de funcionamiento muy marcados. De manera general, eran una medida de control de los movimientos de las poblaciones. Anque eso podía parecer normal hacia las fronteras exteriores, era paradójico que existieran en las fronteras interiores al bloque.

La cortina de hierro suponía cercos de púas, miradores y una vigilancia constante: era la separación territorial entre los dos bloques políticos.

Pero la situación daba igual entre los países hermanos. Primero, ciertas fronteras fueron estrictamente cerradas. La antigua Prusia oriental había sido compartida en 1945: la mitad meridional atribuida a Polonia y la mitad septentrional (la región de Kaliningrado) a la Unión Soviética. En esta zona existía toda una red de carreteras y ferrocarriles entre el norte y el sur que se interrumpió. A lo largo de la frontera soviético-polaca existían siete puntos de tránsito ferroviario; solamente dos eran para coches uno al nivel de Brest-Litovsk, en el centro, el otro al nivel de Przemysl, en el sureste.

De manera general, las fronteras soviéticas eran las más impenetrables, sólo había seis caminos para coches entre el mar Negro y el mar Báltico para ir de un país a otro, y solamente un camino entre la Unión Soviética y Finlandia. Las fronteras cuyo cruce era particular, también eran muy inaccesibles: una docena de caminos para salir de Rumania; solamente dos para salir de Albania (ambos con Yugoslavia), mientras que la frontera 
entre Grecia y Yugoslavia quedaba cerrada. Lo mismo ocurría entre las fronteras de la Unión Soviética y Nonuega.

Por el contrario, Yugoslavia, cuyo rumbo político era diferente, tenía fronteras más abiertas: siete caminos hacia Italia, cuatro hacia Austria, seis a Hungría, tres a Rumania, seis a Bulgaria, dos a Grecia y dos hacia Albania; es decir, treinta caminos.

La fiebre obsidional tenía como fin la de dejar libres, para asuntos militares, regiones enteras (Kaliningrado) y, más allá de eso, la de poner bajo el control del ejército zonas muy extensas alrededor de las fronteras, provocando la dificultade de movimiento (para los rebaños), y un uso muy limitado de las carreteras existentes, particularmente las que permitían comunicar con el oeste.

La apertura relativa de Yugoslavia constituye - sobre todo a partir del 1960 - una excepción la cual permite la movilización para el negocio internacional en eje mayor Trieste-Belgrado con dos cruces: uno hacia Sofía y Estambul, el otro hacia Salónica.

Esta división en compartimentos de Europa es también la representación territorial de una política de autarquía, de movilización de todos los recursos naturales disponibles a escala nacional; de restricción de los cambios internacionales a lo estrictamente necesario, y de manera general, un sistema que favorece los cambios de mercancías, contra los movimientos de las poblaciones; de allí la prevalencia del ferrocarril en relación con la carretera. La única excepción a esas limitaciones era el desarrollo del turismo balneario en las playas de Bulgaria y Rumania a orillas del mar Negro, que provocó la movilización de numerosos grupos de personas.

\section{TIPOLOGÍA DE LAS FRONTERAS CENTRO-EUROPEAS}

En el seno de la Unión Europea, las fronteras interiores se dirigen, por el contrario, hacia su desaparición, lo que permite subrayar las fronteras exteriores. La noción de frontera exterior en la Unión Europea apareció y se ha hecho cada vez más precisa. Al mismo tiempo, sin embargo, el enfoque se ha trasladado de las fronteras territoriales hacia los pasos de entrada aérea, es decir, los aeropuertos.

En 1996, solamente nueve Estados de la Unión Europea, de los 15 que la conforman han firmado los Acuerdos de Schengen sobre la libre circulación de la gente sin control en las fronteras internas.

Asimismo, desde 1994 se ha entablado un proceso de integración progresiva de los países de Europa central a través de acuerdos de asociación con la Unión Europea, pudiendo citar como ejemplos, los siguientes: febrero de 1994: acuerdos de asociación con Hungría y Polonia; 


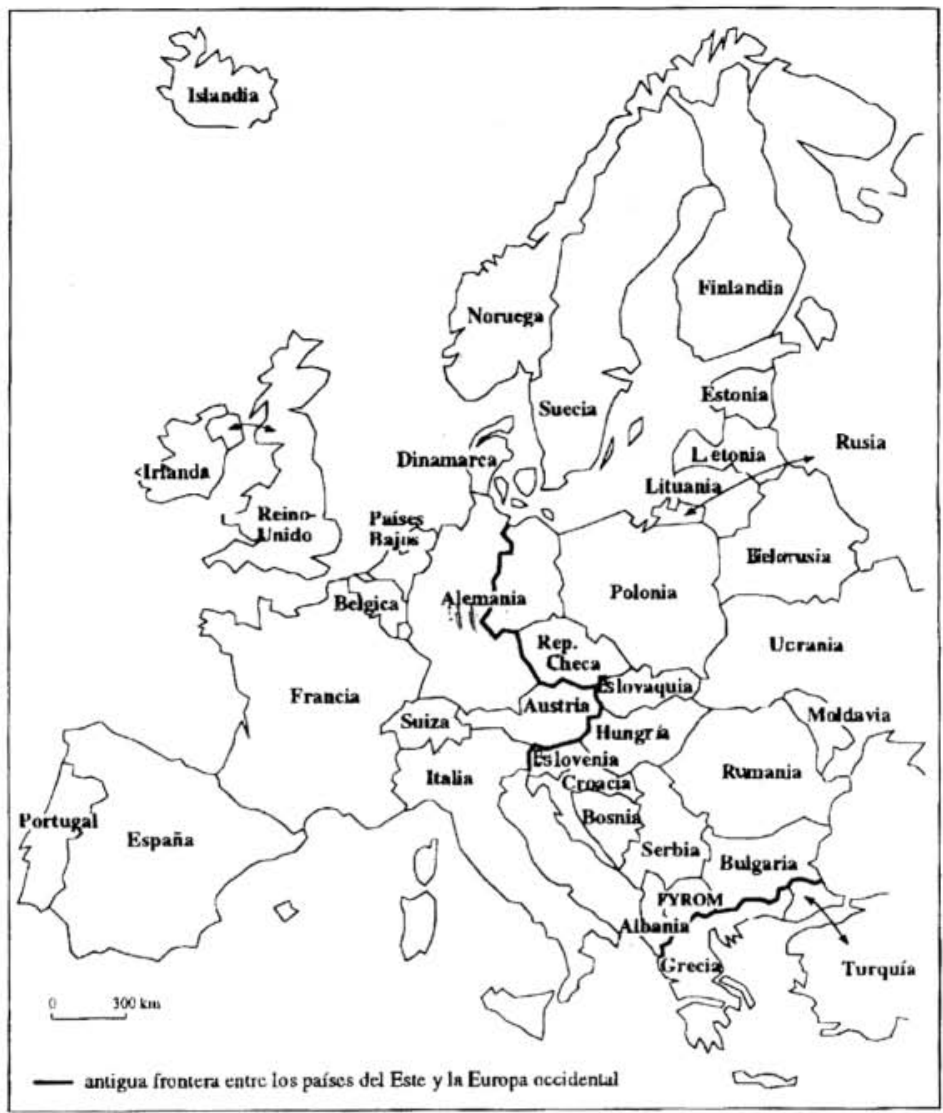

\section{Figura 1.}

febrero 1995: acuerdo de asociación con la República Checa, Eslovaquia, Rumania y Bulgaria; junio de 1995: acuerdos de asociación con Lituania, Letonia y Estonia. En 1996: acuerdo de asociación con Eslovenia. En ese mismo año, cinco países fueron seleccionados por la Unión Europea para ser los primeros en integrarse a dicha organización: Polonia, Hungría, República Checa, Eslovenia y Estonia.

Desde ahí los acuerdos resultan en un ensanchamiento de los límites de la Unión Europea y en la creación, de cierta manera, de una jerarquía entre las fronteras. De este pasado complicado resulta una tipología de fronteras cuya complejidad aumenta de día en día según los acontecimientos. 


\section{Primer tipo}

Son las fronteras de los países de la Europea occidental que colindan con las naciones del sector oriental y central: Alemania (con Polonia y República Checa), Austria (con la República Checa, Eslovaquia, Hungría, y Eslovenia), e Italia (con Eslovenia).

Hay que considerar de manera diferente las fronteras de Finlandia y Noruega con Rusia. Es preciso, en esta perspectiva, no olvidar las fronteras de Grecia con Albania, Macedonia, Bulgaria y tampoco las fronteras de Turquía con Bulgaria.

Existe cierto número de países de Europa central favorecidos por un contacto directo con los países de la Unión Europea. Sin embargo, en Grecia, por ejemplo, las tensiones políticas con Albania y Macedonia y las relaciones a menudo difíciles con Bulgaria, no han permitido el desarrollo normal de los cambios. El número de los caminos abiertos con Bulgaria no ha aumentado, pues los Griegos se han opuesto a la apertura de un paso en el Ródope, por temor a poner en contacto dos pueblos con el mismo idioma (el búlgaro) y la misma religión (musulmana), que viven de un lado $\mathrm{y}$ otro de la frontera.

\section{Secundo tipo}

Son las fronteras interiores de los países del este (salvo la URSS). Esas fronteras no provocan ninguna atracción particular, salvo en ciertos casos de países muy lejos de Europa del oeste, pero que buscan contactos con ella, como Rumania, único país que no tiene frontera directa con la Unión Europea.

En el caso de las fronteras entre países del bloque comunista, se observa solamente un auge considerable en el tráfico de automóviles pero sin aumento de la cantidad de garitas fronterizas, lo que significa filas de espera muy largas.

\section{Tercer tipo}

A esta tipología pertenecen los países asociados a la Unión Europea y a la CEI. Se trata de las fronteras de Rusia, Bielorrusia, Ucrania y Moldavia. Aquí también, las fronteras occidentales de Bielorrusia y Ucrania experimentan un desarrollo continuo en los cambios con el oeste (Polonia y Lituania). En las puertas de Vilnius, en Lituania, por ejemplo, se aprecia un inmenso mercado en un terreno extenso a la entrada de una central térmica, mercado cuyos clientes son en mayoría bielorrusos y ucranianos. 


\section{Cuarto tipo: Las fronteras nacidas de conflictos armados}

Aunque las tensiones no se traduzcan en una guerra necesariamente, la frontera es el vínculo visible de las representaciones antagónicas, particularmente en el caso de que la tensión tenga que ver con la presencia de una minoría nacional.

En esta categoría de fronteras se encuentran las que han sido puestas en tela de juicio por conflictos armados, tales como la antigua Yugoslavia, o la República de Moldavia, aunque esta última es un caso particular. Ya que sale de una de las repúblicas que integraban la Unión Soviética. Su población se compone de $64 \%$ de moldavos de lengua rumana (lengua latina), el resto son rusos y ucranianos rusificados, establecidos por la fuerza en la autoproclamada república de Transdnistria, protegida por el ejército ruso.

\section{EL FUNCIONAMIENTO DE LAS FRONTERAS}

Las fronteras políticas materializan las rupturas territoriales de la nueva organización política de Europa. Esas rupturas construyen de cierta manera, una nueva geografía.

La ventaja otorgada a los cambios en las zonas este-oeste, consiste en dar un avance territorial a todas las partes occidentales de los Estados respecto a las inversiones extranjeras, los empleos y el desarrollo turístico. Los ejemplos son numerosos y significativos.

En el caso de la República Checa, la época que finaliza en 1989, se caracteriza por un esfuerzo inmenso de homogeneización de las condiciones de existencia. En las últimas investigaciones, las reivindicaciones a propósito de los equipos sociales y médicos de alojamiento, pasan a último término, porque la situación existente parece satisfactoria, ya que es igual en todas partes.

Durante la época socialista, las desigualdades proceden de las consecuencias desastrosas de la industrialización, particularmente en el plano de la polución.

Desde 1990, las desigualdades se han extendido más, considerando la proximidad con Alemania. La frontera sajona (ex RDA) recibe inversiones alemanas atraídas por la mano de obra barata y que tiene una larga tradición industrial. En este caso, lo que más importa es la influencia directa de Berlín, que está a sólo $150 \mathrm{~km}$. La penetración de la influencia alemana desde Baviera es más profunda. Muchos son los trabajadores que cada día cruzan la frontera para dirigirse a Alemania, mientras que aquí esperan los que tratan de emigrar al oeste. 
La diferencia de los precios entre los dos lados de la frontera hace surgir varios tráficos. Generalmente numerosos indicios, tales como los depósitos bancarios y las tasas de empleo, prueban el papel de la proximidad con la antigua Alemania del oeste.

Eslovaquia es un ejemplo de traslado al oeste del centro de gravedad. El este del país (región de Kosice) había recibido, durante la época comunista, un gran número de inversiones: la central siderúrgica que utilizaba el carbón de Ostrava en Silesia, el hierro de Ucrania y el gas ruso. Esa ubicación es una trampa.

Por el contrario, la región de Bratislava, gracias a la cual Eslovaquia tiene contacto con Austria y Viena, recibe hoy en día $60 \%$ de las inversiones extranjeras. Bratislava se ha negado a construir un aeropuerto internacional, ya que solamente $60 \mathrm{~km}$ la separan del de Viena.

La evolución regional de Hungría recuerda los ejemplos que acabamos de desarrollar. Todo contribuye desde ahora a la valorización de la mitad occidental de Hungría, al oeste del Danubio. La proximidad de Austria es un elemento esencial de explicación. Los indicios convergen a marcar la buena salud económica de la parte occidental de Hungría: la tasa de desempleo es más baja, los depósitos en los bancos más numerosos y la tasa de suicidio se ha reducido.

Polonia presenta un caso igual con ciertos matices. El efecto en la parte occidental del país se ha dado a partir de 1945. Antes eran provincias totalmente germanizadas. La nueva orientación polaca beneficia a la zona fronteriza, particularmente las ciudades gemelas (una del lado alemán, otra del lado polaco).

Puesto que los precios son más bajos que en Alemania, hay mercados que espontáneamente se abren a orilla de las carreteras del lado polaco para compradores alemanes. Los vendedores llegan de toda Europa oriental. Más allá de las peripecias comerciales, la presión alemana por la tierra, de manera más o menos disimulada, contribuye en aumentar las tensiones.

En la frontera oriental de Polonia, la desigualdad aprovecha a los Polacos que son más ricos que sus vecinos. El control de los flujos provoca bloqueos en la entrada del territorio polaco. Ucranianos y bielorrusos se dirigen a Polonia para trabajar, donde los salarios son más altos, mientras que otros inmigrantes ilegales, procedentes de otros países del mundo, esperan el momento para marcharse a Alemania o a cualquier otro país de la Unión Europea.

A través de estos ejemplos que acabamos de analizar, es posible construir un modelo geográfico de funcionamiento actual de las fronteras en Europa central y oriental. 
Este modelo toma en cuenta, por una parte, las ciudades ubicadas il oeste que tienen una influencia al este.

Generalizando el enfoque, determinamos que dos zonas se beneficiall de los cambios recientes: a) Primero, una zona fronteriza en contacio directo con los países de la Unión Europea; b) Segundo, la zona situadiı alrededor de la capital y de algunas ciudades.

\section{LAS FRONTERAS EMERGENTES; EL EJEMPLO DE LA EX YUGOSLAVIA}

La división política de la ex Yugoslavia, donde las seis repúblicas se han transformado en cinco Estados, es demasiado reciente y cambiante para que podamos hacer conclusiones aún.

Sin embargo, el diseño de las fronteras hace necesarias algunas observaciones: generalmente, las fronteras internas de Yugoslavia son fronteras históricas que siguen los límites sucesivos del imperio otomano y del imperio de los Habsburgo. Desde fines del siglo XVIII, hay una excepción notable: la frontera de Serbia y Macedonia, creada ex nihilo en 1945.

Pero la guerra lo ha cambiado todo, particularmente en Bosnia, que es un país dividido entre dos entidades por los Acuerdos de Dayton, pues la que pudiera considerarse la tercera entidad, la federación croato-musulmana, queda tan sólo como una ficción aún.

Ahora bien, la frontera entre la República Servia de Bosnia, por una parte, y la federación croato-musulmana, por otra, es la consecuencia de la guerra: es una línea de alto al fuego resultado primero de la repartición étnica antes de 1991, y después de la purificación étnica. La configuración de las fronteras es, pues, muy compleja, con una serie de senderos de los cuales, el de Brcko es el más raro, con una anchura inferior a cinco kilómetros en el valle de Save, que une las dos zonas de la República Servia de Bosnia. Pero no es el único caso: el enclave musulmano de Gorazde comunica con el resto de la federación croato-musulmana a través de otro sendero igual.

Todo parece demostrar que la Federación musulmana decidida por la voluntad estadounidense no tiene que ver con ninguna voluntad política local. Además, las consecuencias demográficas de la guerra serán probablemente muy lentas de borrar. Ciertas regiones han sido desalojadas de su población. Otras se han convertido en refugios, cuya población ha aumentado rápidamente.

Aunque aún falta información de muchas otras regiones, las regionesrefugios, son las que desde el principio del conflicto, han permanecido en poder del grupo mayoritario, entre las cuales se pueden mencionar: $\mathrm{La}$ 
costa adriática, donde se han replegado poblaciones croatas del interior. Voivodina, donde se refugiaron servios de Eslovenia. La región de Banja Luka. El rincón bosniaco entre Sarajevo y Tuzla, esta última ciudad que tenía 180000 habitantes en 1991, actualmente alojaría 900000 personas. Zagreb y Belgrado, es evidente, han recibido un gran número de refugiados.

De manera general, la guerra ha acelerado el proceso de urbanización. De modo contrario, regiones enteras han sido abandonadas por su población, sobre todo en las montañas de Krajina, una región croata poblada antiguamente por los servios, y otra zona de Bosnia occidental, ahora trasladada al poder militar bosniaco. Esta región montañosa no será fácil de poblar de nuevo, y probablemente los refugiados preferirán permanecer en las ciudades, aun en condiciones difíciles, en lugar de dirigirse a una región rural pobre y enclavada.

Por todas estas razones, las nuevas fronteras servirán para delimitar porciones de desiertos.

El enfoque creado por esas devastaciones es así. ¿Volverán las poblaciones? No solamente la partición étnica está en contra a esa esperanza, sino también para acentuar el carácter monoétnico de las poblaciones divididas por las fronteras. Los campesinos que han huido de sus aldeas hacia ciudades vecinas o hacia otros lugares, no manifiestan ninguna voluntad de volver, sobre todo los más jóvenes.

La única solución razonable está en la reconstitución de un conjunto económico de la Europa del sureste, integrado progresivamente en la Unión Europea. 